\title{
A NEW BROADBAND CIRCULAR PATCH ANTENNA
}

\author{
Supriyo Dey, C. K. Aanandan, P. Mohanan, and K. G. Nair \\ Department of Electronics \\ Cochin University of Science \& Technology \\ Kochi 682 022. India
}

\section{KEY TERMS}

Antenna, circular paich, broadband

\section{ABSTRACT}

A simple technique to improve the impedance bandwidth of a circular microstrip patch antenna using two sectoral slots is proposed. Using this design more than $5 \%$ impedance bandwidth is obtained. The added adiantage of this new antenna is that it can be fed by a $50-\Omega$ microstrip line. (c) 1994 John Wiley \& Sons, Inc.

\section{INTRODUCTION}

Microstrip antennas are quickly replacing conventional antennas due to advantages such as light weight, small size, low production cost, and conformal nature. The commonly used radiating elements are rectangular and circular patches. The inherent disadvantage of these antennas is their extremely narrow impedance bandwidth. Although numerous methods are described in the literature to improve the impedance

circular microstrip patch. This is mainly due to the limifdi use of the circular patch antenna because of high input inpedance along its circumference, which restricts the direct use of a $50-\Omega$ microstrip line as feed. A method to overcome this constraint has already been proposed by the authors, wherein, a sectoral slot shunted with a conducting strip is made on the patch [5]. This antenna shows wide variation in input impedance along the circumference and thus can easily be matched with a microstrip line of any impedance.

One of the techniques commonly used to enhance the bandwidth of the circular patch is by using a parasitic element over the patch in a stacked fashion [6]. Another conventional method is the use of a thick dielectric substrate to inprove the impedance bandwidth of the circular patch antenna [7]. Even though there is substantial improvement in the impedance bandwidth of the antennas, in both cases the structure becomes bulky and complex. In this article we report a new technique to enhance the impedance bandwidth of circular patch antenna on thin dielectric substrates.

\section{DESIGN AND EXPERIMENTAL DETAILS}

The schematic diagram of the antenna is shown in Figure 1. Two sectoral slots are made on the patch surface. The presence of the sectoral slots on the patch causes the antenna to resonate at two adjacent frequencies, which results in the enhancement of the impedance bandwidth.

As a typical example, an antenna is fabricated on a dielectric substrate having thickness $h=0.16 \mathrm{~cm}$ and dielectric constant $\epsilon_{r}=4.5$. The radius $r$ of the patch is $4.95 \mathrm{~cm}$ and the sectoral slot angle $\theta$ is $6^{\circ}$. The angular position of the $50-\Omega$ feed point from the center of the sectoral slot $\phi$ is $30^{\circ}$.

The VSWR plot of the antenna is shown in Figure 2. The 2:1 VSWR bandwidth of the antenna is $47.66 \mathrm{MHz}$ and the central frequency is at $882.7 \mathrm{MHz}$. This corresponds to a $5.4 \%$ impedance bandwidth. This is much larger than the impedance bandwidth of $1 \%$ to $2 \%$ of ordinary circular patch antennas.

The $\mathrm{E}$ - and $\mathrm{H}$-plane radiation patterns of the antenna at the central frequency and the two end frequencies (normal-

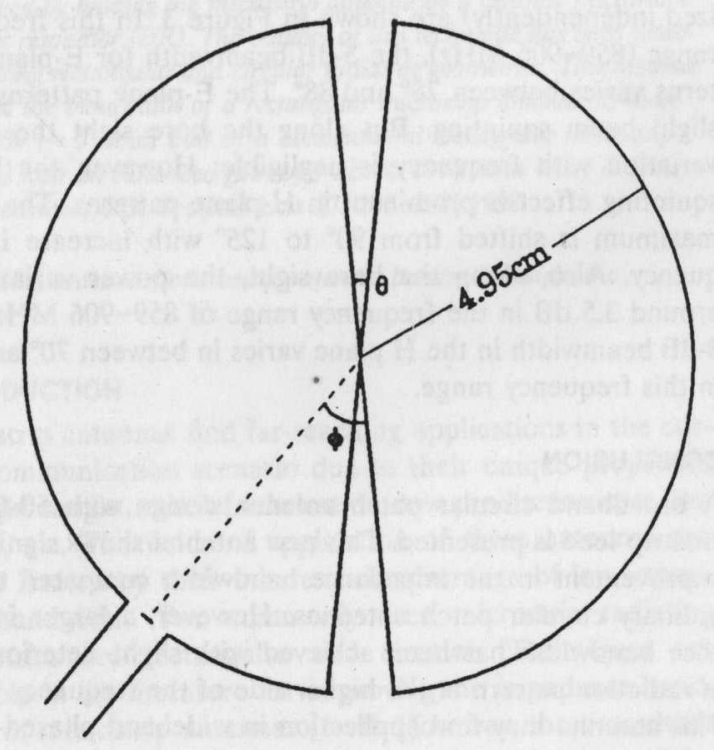

Figure 1 Schematic diagram of the antenna 


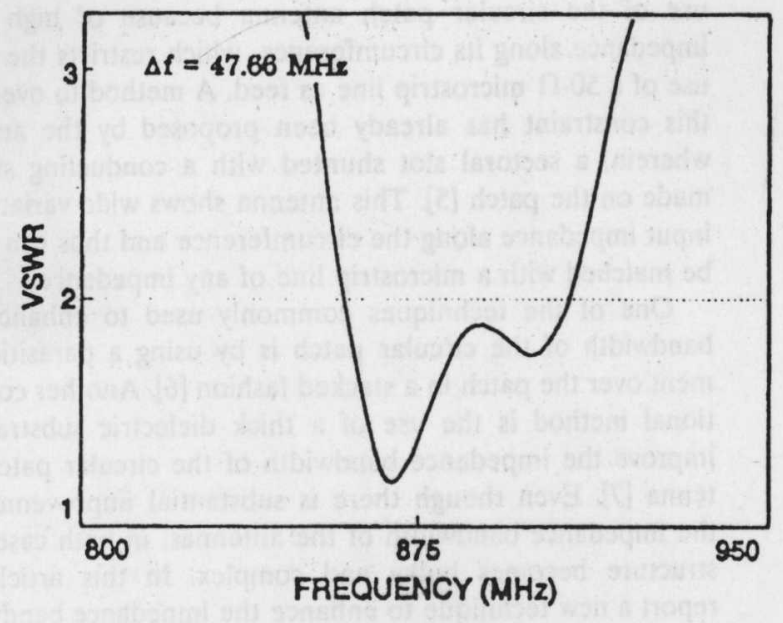

Figure 2 VSWR plot of the antenna
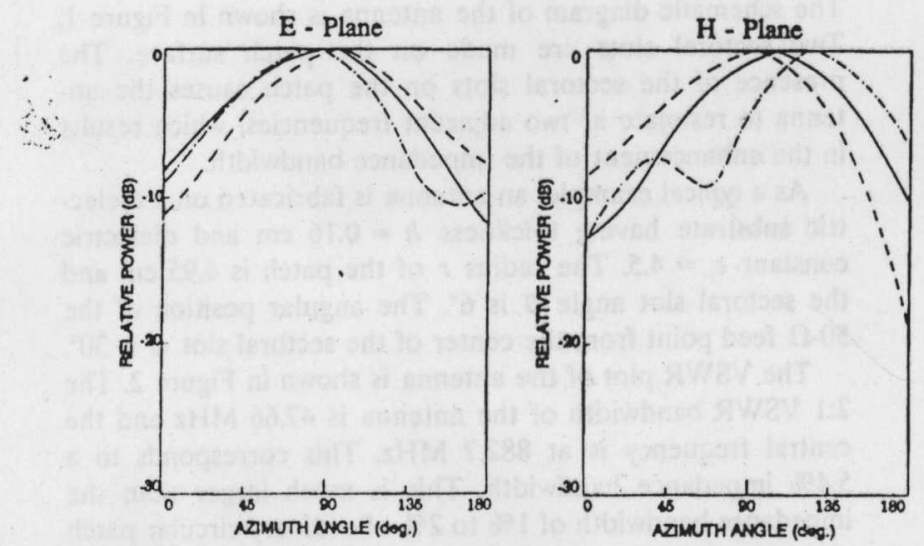

Figure 3 Radiation patterns. Dashed line, $859 \mathrm{MHz}$; solid line, 879 $\mathrm{MHz}$; dot-dashed line, $906 \mathrm{MHz}$

ized independently) are shown in Figure 3. In this frequency range (859-906 MHz), the 3-dB beamwidth for E-plane patterns varies between $78^{\circ}$ and $88^{\circ}$. The E-plane patterns show slight beam squinting. But along the bore sight the power variation with frequency is negligible. However, the beamsquinting effect is prominent in H-plane patterns. The beam maximum is shifted from $90^{\circ}$ to $125^{\circ}$ with increase in frequency. Also, along the bore sight, the power variation is around $3.5 \mathrm{~dB}$ in the frequency range of $859-906 \mathrm{MHz}$. The 3- $\mathrm{dB}$ beamwidth in the $\mathrm{H}$ plane varies in between $70^{\circ}$ and $80^{\circ}$ in this frequency range.

\section{CONCLUSION}

A broadband circular patch antenna design with $50-\Omega \mathrm{mi}-$ crostrip feed is presented. This new antenna shows significant improvement in the impedance bandwidth compared to the ordinary circular patch antennas. However, a larger impedance bandwidth has been achieved with slight deterioration in radiation pattern at the higher side of the frequency band. This antenna may find application in wideband phased-array systems.

\section{ACKNOWLEDGMENT}

Supriyo Dey acknowledges University Grants Commission, Govt. of India, for providing a research fellowship.

\section{REFERENCES}

1. P. S. Hall, C. Wood, and C. Garrett, "Wide Bandwidth Micro Patch Antennas for Circuit Integration," Electron. Lett., Vol No. 15, Sept. 1979, pp. 458-459.

2. C. Wood, "Improved Bandwidth of Microstrip Antennas U Parasitic Elements," Proc. Inst. Elec. Eng. MOA, 1980, p. 127.

3. G. Kumar and K. C. Gupta, "Non-Radiating Edges and I Edges Gap-Coupled Multiple Resonator Broad-Band Micros Antennas," IEEE Trans. Antennas Propagat., Vol. AP-33, Nt Feb. 1985, pp. 173-178.

4. C. K. Aanandan and K. G. Nair, "Compact Broadband Micrc. Antenna," Electron. Lett., Vol. 22, No. 20, Oct. 1986, 1064-1065.

5. S. Dey, C. K. Aanandan, P. Mohanan, and K. G. Nair, Modified Circular Microstrip Antenna," Electron. Lett., Vol. No. 12, June 1993, pp. 1126-1127.

6. S. A. Long and M. D. Walton, "A Dual-Frequency Stacked C: lar Disc Antenna," IEEE Trans. Antennas Propagat., Vol. A? No. 3, March 1979, pp. 270-273.

7. P. S. Hall, J. S. Dahele, and P. M. Haskins, "Microstrip ?a Antennas on Thick Substrate," Int. Symp. Dig. Antennas Propa Soc., June 1989, pp. 458-462.

Receited 3-2.

Microwave and Optical Technology Letters, 7/13, 604-605 (c) 1994 John Wiley \& Sons, Inc.

CCC $0895-2477 / 94$ 
tion capacitance model can be used to describe this process:

$$
C_{\text {ramp }}=\frac{m}{(1-V / \phi)^{n}}
$$

where $m$ and $n$ are constants which can be determined by wing the continuity conditions for the beginning and end of this process, i.e.,

$$
\begin{array}{ll}
C_{\text {ramp }}=C_{1}, & \text { when } V=V_{1} \\
C_{\text {ramp }}=C_{2}, & \text { when } V=V_{2} .
\end{array}
$$

Using Eqs. (5) and (6), we obtain

$$
n=\frac{\log \left(\frac{C_{1}}{C_{21}}\right)}{\log \left(\frac{\phi-V_{2}}{\phi-V_{1}}\right)} \text { and } m=C_{2}\left(1-\frac{V_{2}}{\phi}\right)^{n} \text {. }
$$

Combining Eqs. (2), (3), and (5), we obtain the complete $C-V$ model of the SRD as

$$
C= \begin{cases}\frac{C_{0}}{(1-V / \phi)^{\gamma}}, & V \leq V_{1} \\ \frac{m}{(1-V / \phi)^{n}}, & V_{1}<V<V_{2} \\ C_{f 0} \exp \left(\frac{q V}{\eta k T}\right), & V \geq V_{2} .\end{cases}
$$

\section{DISCUSSION}

Through the measured $C-V$ result, we have modeled the SRD using Eq. (8). This model can be easily implemented in a circuit simulator. The $R_{s}-V$ characteristic is more complicated. Just before conduction of the diode starts, $R_{s}$ first decreases, then in the transition region rapidly increases, reaching a peak value, and finally drops again. However, $R_{s}$ does not vary much with the voltage. So, the values of $R_{s}$ extracted through dc measurements may still be used to model the diode.

\section{CONCLUSION}

This paper has presented a fast and accurate technique for the characterization of microwave step recovery diodes. A simple transmission line test fixture is designed for the characterization of SRD chips. Two SRD chips are measured by using this technique. Based on the measured results, a more accurate model of the step recovery diode has been developed.

\section{REFERENCES}

1. J. L. Moll and S. A. Hamilton, "Physical Modeling of the Step Recovery Diode for Pulse and Harmonic Generation Circuits," Proc. IEEE, Vol. 57, July 1969, pp. 1250-1259.

2. S. Hamilton and R. Hall, "Shunt Mode Harmonic Generation Using Step Recovery Diodes," Microwave J., Apr. 1967, pp. 69-78.

3. J. Zhang and A. V. Räisänen, "A New Model of Step Recovery Diodes for CAD," 1995 Int. IEEE MTT-S Symp. Dig., Orlando, FL, May 1995, pp. 1459-1462.

4.W. Konrath and H. Brauns, "First Fully CAD of a $K$-Band Sampling Phase Detector Using Periodic Steady State Analysis and Sophisticated SRD-Modeling," 26th European Microwave Conf., Prague, Czech Republic, Sept. 1996, pp. 973-976. 
5. J. Zhang and A. V. Räisänen, "Computer-Aided Design of Step Recovery Diode Frequency Multipliers," IEEE Trans. Microwave Theory Tech., Vol. 44, Dec. 1996, pp. 2612-2616.

6. O. Boric, T. J. Tolmunen, E. Kollberg, and M. A. Frerking, "Anomalous Capacitance of Quantum Well Double-Barrier Diodes," Int. J. Infrared Millimeter Waves, Vol. 13, No. 6, 1992, pp. 799-814.

7. W. M. Sharpless, "Gallium Arsenide Point-Contact Diodes," IRE Trans. Microwave Theory Tech., Vol. MTT-9, No. 1, 1961, pp. 6-10.

8. WILTRON Product Catalog.

9. S. Lidholm, "Low-Noise Mixers for $80-120 \mathrm{GHz}$," Res. Rep. 129, Research Lab. of Electronics, Chalmers Univ. of Sweden, 1977, 139 pp.

10. M. T. Faber, J. Chramiec, and M. E. Adamski, Microwave and Millimeter-Wave Diode Frequency Multipliers, Artech House, Norwood, MA, 1995.

11. "Appendix A-Using Symbolically-Defined Devices (SDDs)," HP MDS Designer's Task Reference, Vol. 2-Creating Circuits as Schematics, 1995.

(C) 1998 John Wiley \& Sons, Inc.

CCC 0895-2477/98 